\title{
Mechanisms of CBF Augmentation during Hypoxia in Cats: Probable Participation of Prostacyclin, Nitric Oxide and Adenosine
}

\author{
Kazuo Isozumi, Yasuo Fukuuchi, Hidetaka Takeda and Yoshiaki Itoh \\ Department of Neurology, School of Medicine, Keio University, Tokyo, Japan
}

(Received for publication on August 17, 1993)

\begin{abstract}
To elucidate the mechanisms of CBF augmentation during hypoxemic hypoxia, we applied continuous monitoring of $\mathrm{CBF}$ and metabolism to examine the participation of prostacyclin, nitric oxide (NO), and/or adenosine in these mechanisms. Cats $(n=32)$ were anesthetized and ventilated artificially. Cerebrovascular reactivity to hypoxia was assessed by changes in $\mathrm{CBF}$, brain tissue oxygen and carbon dioxide tensions, and mean arterial blood pressure $\left(\triangle \mathrm{CBF}, \triangle \mathrm{BrPO}_{2}, \triangle \mathrm{BrPCO}_{2}\right.$, and $\left.\triangle \mathrm{MABP}\right)$ during a 3-min inhalation of $10 \% \mathrm{O}_{2}+90 \% \mathrm{~N}_{2}$ before and after the intracarotid administration of (1) indomethacin ( $1 \mathrm{mg} / \mathrm{kg}$, a cyclooxygenase inhibitor, $\mathrm{n}=11$ ), (2) $\mathrm{L}-\mathrm{N}^{\mathrm{G}}$-monomethyl-arginine (LNMMA, $1 \mu \mathrm{mol} / \mathrm{kg} / \mathrm{min}$, an inhibitor of nitric oxide synthesis, $n=11)$, and (3) caffeine $(20 \mathrm{mg} / \mathrm{kg}$, an adenosine antagonist, $\mathrm{n}=10$ ). $\mathrm{BrPO}_{2}$ decreased significantly in all groups during the produced hypoxemic hypoxia. CBF significantly increased in this state before the administration of indomethacin, LNMMA, or caffeine, whereas it contrastively did not significantly increase after the administration of indomethacin or caffeine. In addition, CBF significantly decreased under hypoxia during the administration of LNMMA. Taken together, these results suggest that prostacyclin ( $\mathbf{P G I}_{2}$ ), nitric oxide (NO), and adenosine may jointly participate in CBF augmentation during hypoxia. (Keio J Med 43 (1): 31-36, March 1994)
\end{abstract}

Key words: cerebral blood flow, vasodilatation, indomethacin, $\mathbf{L}^{-N^{\mathbf{G}}}$-monomethyl-arginine (LNMMA), caffeine

\section{Introduction}

General agreement exists concerning the relation between hypoxemic hypoxia and cerebral blood flow (CBF), i.e. CBF does not substantially change during alterations of arterial oxygen tension $\left(\mathrm{PaO}_{2}\right)$ within the physiological range, whereas cerebral arterioles dilate and CBF increases when $\mathrm{PaO}_{2}$ drops below $50-60 \mathrm{mmHg}$ (hypoxemia). ${ }^{1,2}$ Although the long-standing lactic acidosis theory ${ }^{2}$ has been applied in many cases to explain the brain's hypoxic hyperemia mechanism, several other mechanisms have also been postulated and discussed.

Of several vasodilators to be considered, participation of eicosanoids in the regulation of CBF received initial attention. ${ }^{3-5}$ Among them, prostaglandin $\mathrm{I}_{2}\left(\mathrm{PGI}_{2}\right.$, prostacyclin), which is a product of cyclooxygenase, is one of the vascular system's main metabolites of arachidonic acid and is dominantly provided by the endothelial cells. ${ }^{6}$ Since prostacylin relaxes or dilates blood vessels, there is a possibility it affects hypoxic hyperemia of the brain.

Vascular dilation by various kinds of vasoactive substances is also known to be mediated by endotheliumderived relaxing factors (EDRFs), ${ }^{7}$ with one EDRF having been specifically identified as nitric oxide (NO), i.e. it is formed from the terminal guanidino nitrogen of L-arginine via the action of NO synthase (NOS) ${ }^{8.9}$ Continuous NO production appears to occur under resting conditions in cerebral vascular beds, thereby imparting a vasodilatory "tone". ${ }^{10}$ However, until recently limited information was available on the relationship between hypoxic hyperemia and NO. ${ }^{9,11}$

A third vasodialtor ganing research attention is the nucleoside adenosine. Among the high energy phosphate

五十棲一男, 福内靖男, 武田英孝, 伊藤義彰

Reprint requests to: Dr Kazuo Isozumi, Department of Neurology, School of Medicine, Keio University, 35 Shinanomachi, Shinjuku-ku, Tokyo 160 , Japan 
compounds found in the brain, adenosine triphosphate (ATP) exists in a concentration of $3 \mu \mathrm{mol} / \mathrm{g}$, being most abundant among the purine nucleotides. When the brain reaches a hypoxic condition, ATP decreases immediately, adenosine begins to increase within a few seconds followed by an increase in inosine, and finally hypoxanthine increases. ${ }^{12}$ Since adenosine affects cerebral vasodilatation, it has been proposed as one modulator of CBF regulation. ${ }^{12-15}$

To elucidate the mechanisms of CBF augmentation during hypoxemic hypoxia, the present study uses continuous monitoring of $\mathrm{CBF}$ and metabolism ${ }^{16-18}$ to examine the paticipation of prostacyclin, $\mathrm{NO}$, and/or adenosine in these mechanisms.

\section{Materials and Methods}

Thirty-two cats weighing $2.3-3.4 \mathrm{~kg}$ (mean $2.8 \mathrm{~kg}$ ) were anesthetized with an intraperitoneal injection of $\alpha$-chloralose $(50 \mathrm{mg} / \mathrm{kg})$ and urethane $(500 \mathrm{mg} / \mathrm{kg})$ and locally with $0.5 \%$ procaine hydrochloride. After tracheostomy, they were immobilized with alcuronium chloride $(0.6-0.8 \mathrm{mg} / \mathrm{kg})$ and a tracheal cannula was connected to a variable speed respirator pump (Harvard Model 662, Harvard, MA, USA). As the initial condition the respiration rate was set at 20 strokes/min and the stroke volume at $10 \mathrm{ml} / \mathrm{mg}$. Abdominal aortic pressure was measured with a pressure transducer (Statham P23IDb, Gould, Oxnard, CA, USA) connected to a polyethylene tube inserted into the abdominal aorta through the left femoral artery. A polyethylene tube was inserted into the right femoral artery for blood gas sampling and another into the right femoral vein for intravenous injection of drugs. A fourth tube inserted retrogradely into the left lingual artery enabled durg injection into the carotid artery. Throughout the experiment the rectal temperature of cats was kept at $37^{\circ} \mathrm{C}$ by means of heating blankets.

A sampling tube connected to a gas analyzer (Engström Eliza $\mathrm{CO}_{2}$ and $\mathrm{O}_{2}$ Analyzer) was inserted into the tracheal cannula to continuously record alveolar $\mathrm{CO}_{2}$ and inspiratory $\mathrm{O}_{2}\left(\mathrm{~F}_{1} \mathrm{O}_{2}\right)$ concentration. The skull was fixed in a stereotactic head holder (Type SN-1, Narishige, Tokyo, Japan) and the scalp and dura over the left parietal cortex region were removed. $\mathrm{PO}_{2}$ and $\mathrm{PCO}_{2}$ electrodes and a laser Doppler probe (Type ALF21, Advance, Tokyo, Japan) were gently attached to the exposed cerebral cortex by adjustable rods with springs. ${ }^{16,17}$ Cortical blood flow was also monitored using a thermistor placed gently on the cortex ${ }^{16,18}$ i.e. variations in brain temperature qualitatively reflect continuous changes in $\mathrm{CBF}$, with increases in temperature indicating increased CBF and vice versa. ${ }^{16,18}$ The output signal from the $\mathrm{PO}_{2}$ electrode was amplified by a gas analyzer (Model 160, Beckman Toshiba, Tokyo, Japan), while that from the
$\mathrm{PCO}_{2}$ electrode by a pH meter (Model 22, Radiometer, Copenhagen, Denmark). Both parameters were continuously recorded on a polygraph (Type R-56M3, Rikadenki, Tokyo, Japan). Electrode calibration was performed with $100 \% \mathrm{~N}_{2}$ and $5 \% \mathrm{O}_{2}+95 \% \mathrm{~N}_{2}$ for the $\mathrm{PO}_{2}$ electrode; and $5 \% \mathrm{CO}_{2}+95 \% \mathrm{~N}_{2}$ and $10 \% \mathrm{CO}_{2}+$ $90 \% \mathrm{~N}_{2}$ for the $\mathrm{PCO}_{2}$ one. Arterial blood $\mathrm{PO}_{2}, \mathrm{PCO}_{2}$, and $\mathrm{pH}$ were measured with a blood gas analyzer (PHM71, Radiometer, Copenhagen, Denmark).

Cerebrovascular reactivity to hypoxia was assessed by changes in CBF, brain tissue oxygen and carbon dioxide tensions, and mean arterial blood pressure $(\triangle \mathrm{CBF}$, $\triangle \mathrm{BrPO}_{2}, \triangle \mathrm{BrPCO}_{2}$, and $\triangle \mathrm{MABP}$ ) during and after a 3min inhalation of $10 \% \mathrm{O}_{2}+90 \% \mathrm{~N}_{2}$. Arterial blood was sampled before and immediately after this 3-min inhalation.

The animals were divided into 3 groups for the following described experiments.

Experiment 1: Eleven cats were used to examine cerebrovascular reactivity to hypoxia before and after an intracarotid injection of indomethacin (a competitive inhibitor of cyclooxygenase, $1 \mathrm{mg} / \mathrm{kg}$ ). CBF was evaluated by the laser Doppler method.

Experiment 2: Eleven cats were used to examine cerebrovascular reactivity to hypoxia before, during, and $60 \mathrm{~min}$ after cessation of an intracarotid continuous injection of $\mathrm{L}-\mathrm{N}^{\mathrm{G}}$-monomethyl-arginine (a competitive inhibitor of NOS, LNMMA, $1 \mu \mathrm{mol} / \mathrm{kg} / \mathrm{min}$ ). $\triangle \mathrm{CBF}$ was evaluated by the thermistor method.

Experiment 3: Ten cats were used to examine cerebrovascular reactivity to hypoxia before and after an intracarotid injection of caffeine (a competitive antagonist of adenosine, $20 \mathrm{mg} / \mathrm{kg}$ ). $\triangle \mathrm{CBF}$ was evaluated by the thermistor method.

The data of $\triangle \mathrm{BrPO}_{2}, \triangle \mathrm{BrPCO}$, and $\triangle \mathrm{MABP}$ are shown as mean $\pm \mathrm{SD}$. The $\triangle \mathrm{CBF}$ data obtained by the laser Doppler method are shown as \% changes from the pre-hypoxic control state, whereas that by the thermistor method by the number of the animals whose CBF (brain temperature) increased or decreased from the prehypoxic control state. Statistical analysis was performed using the Student's paired t-test for all data except $\triangle C B F$ by the thermistor method in which the sign test was adopted. A p value less than 0.05 was considered significant.

\section{Results}

Table 1 summarizes changes in the arterial blood gas of 10 cats before and just after the 3-min inhalation of $10 \% \mathrm{O}_{2}+90 \% \mathrm{~N}_{2}$, where $\mathrm{PaO}_{2}$ at the end of hypoxia 
Table 1 Blood Gas Analysis

\begin{tabular}{lccc}
\hline \hline & $\begin{array}{c}\mathrm{PaO}_{2} \\
(\mathrm{mmHg})\end{array}$ & $\begin{array}{c}\mathrm{PaCO}_{2} \\
(\mathrm{mmHg})\end{array}$ & $\mathrm{pH}$ \\
\hline Control & $95.4 \pm 11.7$ & $32.5 \pm 3.4$ & $7.290 \pm 0.061$ \\
Hypoxia & $38.5 \pm 6.0$ & $30.4 \pm 5.7$ & $7.346 \pm 0.067$ \\
& $\mathrm{p}<0.01$ & n.s. & n.s. \\
\hline
\end{tabular}

Changes in the arterial blood gas of 10 cats before (Control) and immediately after a 3-min inhalation of $10 \% \mathrm{O}_{2}+90 \% \mathrm{~N}_{2}$ (Hypoxia). Mean \pm SD, n.s.: non-significant change.

was $38.5 \pm 6.0 \mathrm{mmHg}$; being significantly lower $(\mathrm{p}<0.01)$ than the control value $(95.4 \pm 11.7 \mathrm{mmHg})$. Note arterial carbon dioxide tension $\left(\mathrm{PaCO}_{2}\right)$ and $\mathrm{pH}$ did not significantly change.

\section{Cerebrovascular response to hypoxia following indomethacin administration (Experiment 1)}

Figure 1 indicates the effect of hypoxia $\left(10 \% \mathrm{O}_{2}+\right.$ $90 \% \mathrm{~N}_{2}$ ) on $\mathrm{CBF}$ and metabolism before and after the administration of indomethacin $(n=11)$. Before indomethacin administration, CBF significantly $(\mathrm{p}<0.05)$ increased to a maximum of $17.1 \pm 18.5 \%$ at $3 \mathrm{~min}$, with a significant $(\mathrm{p}<0.01)$ decrease correspondingly occurring in $\mathrm{BrPO}_{2}(-11.6 \pm 8.0 \mathrm{mmHg})$. In contrast, after the administration, CBF did not increase significantly at $3 \mathrm{~min}(6.4 \pm 22.3 \%)$ in spite of a significant

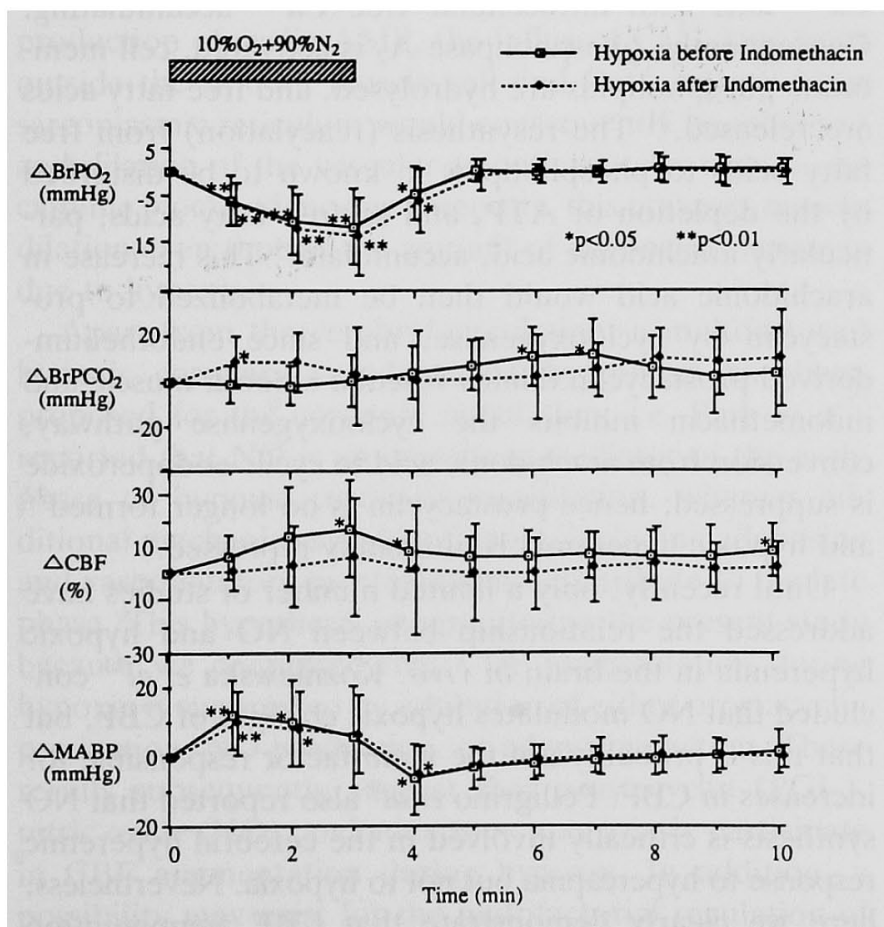

Fig 1 Changes in cerebrovascular reactivity to hypoxia (laser Doppler method) before and after the administration of indomethacin $(n=11)$. *, **: Significant change from $0 \mathrm{~min}$. $(\mathrm{p}<0.01)$ decrease in $\mathrm{BrPO}_{2}(-13.7 \pm 8.0 \mathrm{mmHg})$.

$\mathrm{BrPCO}_{2}$ showed non-specific changes before and after the administration of indomethacin, a behavior indicating indomethacin did not substantially affect cerebral metabolism in the present experimental condition. Since the amount of decrease in $\mathrm{BrPO}_{2}$, as well as the amount of increase in MABP are not different before and after the administration of indomethacin, CBF augmentation during hypoxia was obviously suppressed by its administration.

\section{Cerebrovascular response to hypoxia following LNMMA} administration (Experiment 2)

Figure 2 shows the effect of hypoxia $\left(10 \% \mathrm{O}_{2}+90 \%\right.$ $\mathrm{N}_{2}$ ) on CBF and metabolism before, during, and after the administration of LNMMA $(n=11)$. Before LNMMA administration, $\mathrm{CBF}$ at $3 \mathrm{~min}$ significantly increased $(\mathrm{p}<0.01)$ in all 11 animals, with a corresponding significant decrease $(\mathrm{p}<0.01)$ in $\mathrm{BrPO}_{2}(-20.5 \pm 16.4$ $\mathrm{mmHg}$ ). However, $\mathrm{CBF}$ at $10 \mathrm{~min}$ significantly decreased $(\mathrm{p}<0.01)$ during the administration in all 11 enimals in spite of a significant decrease $(\mathrm{p}<0.01)$ in $\mathrm{BrPO}_{2}$ occurring at $3 \mathrm{~min}(-10.9 \pm 8.2 \mathrm{mmHg})$. CBF at $2 \mathrm{~min}$ once again significantly increased $(\mathrm{p}<0.01)$ (increased in 7 animals/unchanged in 4) $60 \mathrm{~min}$ after cessation of

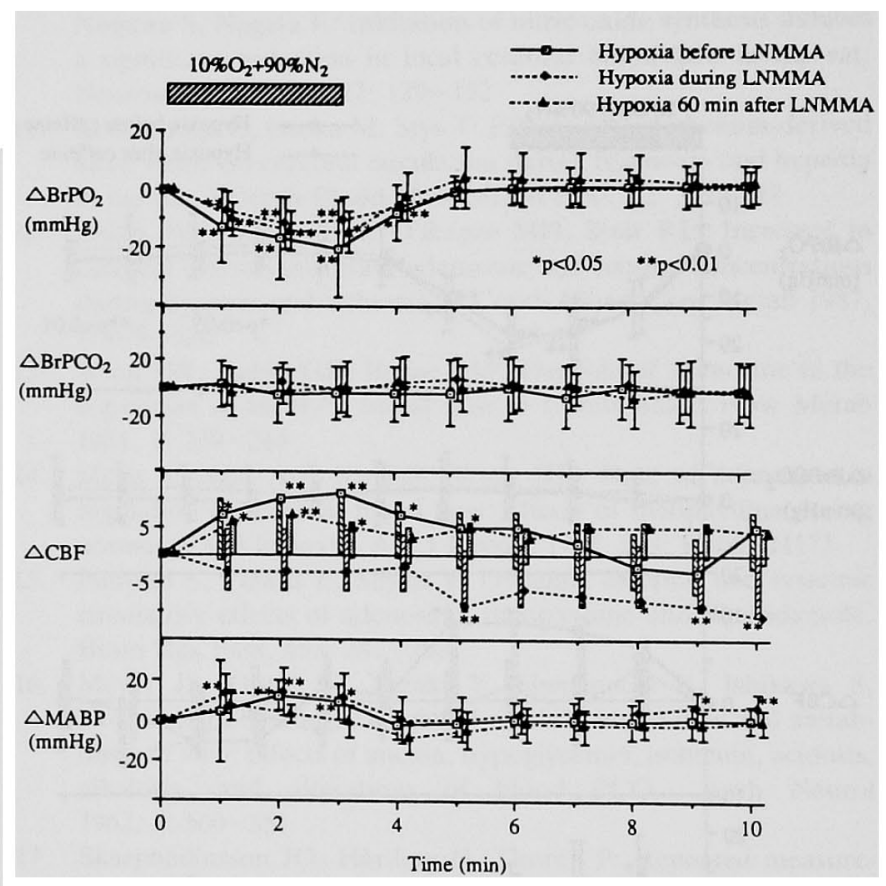

Fig 2 Changes in cerebrovascular reactivity to hypoxia (thermistor method) before, during and after the administration of LNMMA $(\mathrm{n}=11) .{ }^{*},{ }^{* *}$ : Significant change from $0 \mathrm{~min}$. Bar height for $\mathrm{CBF}$ represents the number of affected animals, i.e. the positive length indicates the number of animals with an increased CBF and negative length those with a decreased value. The circles, triangles, or squares correspond to a difference between the numbers of increased and decreased animals; the number of unchanged animals was not included. 
LNMMA. $\mathrm{BrPCO}_{2}$ showed no remarkable changes before, during and after the administration of indomethacin, which indicates LNMMA did not substantially affect cerebral metabolism in the present experimental condition. Thus, like indomethacin, the amount of decrease in $\mathrm{BrPO}_{2}$ and increase in MABP were not comparatively different before, during, or after the administration of LNMMA, hence CBF augmentation during hypoxia was suppressed by its administration.

\section{Cerebrovascular response to hypoxia following caffeine administration (Experiment 3)}

Figure 3 indicates the effect of hypoxia $\left(10 \% \mathrm{O}_{2}+\right.$ $90 \% \mathrm{~N}_{2}$ ) on $\mathrm{CBF}$ and metabolism before and after the administration of caffeine. Before the administration, CBF at 3 min significantly increased $(\mathrm{p}<0.01)$ (increased in 9 animals/unchanged in 1), with a corresponding significant decrease $(\mathrm{p}<0.01)$ occurring in $\mathrm{BrPO}_{2}(-19.0$ $\pm 6.7 \mathrm{mmHg}$ ). After administration, however, no significant increase in $\mathrm{CBF}$ took place (increased in 5 animals/unchanged in $2 /$ decreased in 3 ) in spite of a significant decrease $(\mathrm{p}<0.01)$ in $\mathrm{BrPO}_{2}(-21.3 \pm 7.4$ $\mathrm{mmHg}$ ) at the same time. $\mathrm{BrPCO}_{2}$ showed no remarkable changes before and after the administration of caffeine, which indicates caffeine did not substantially affect

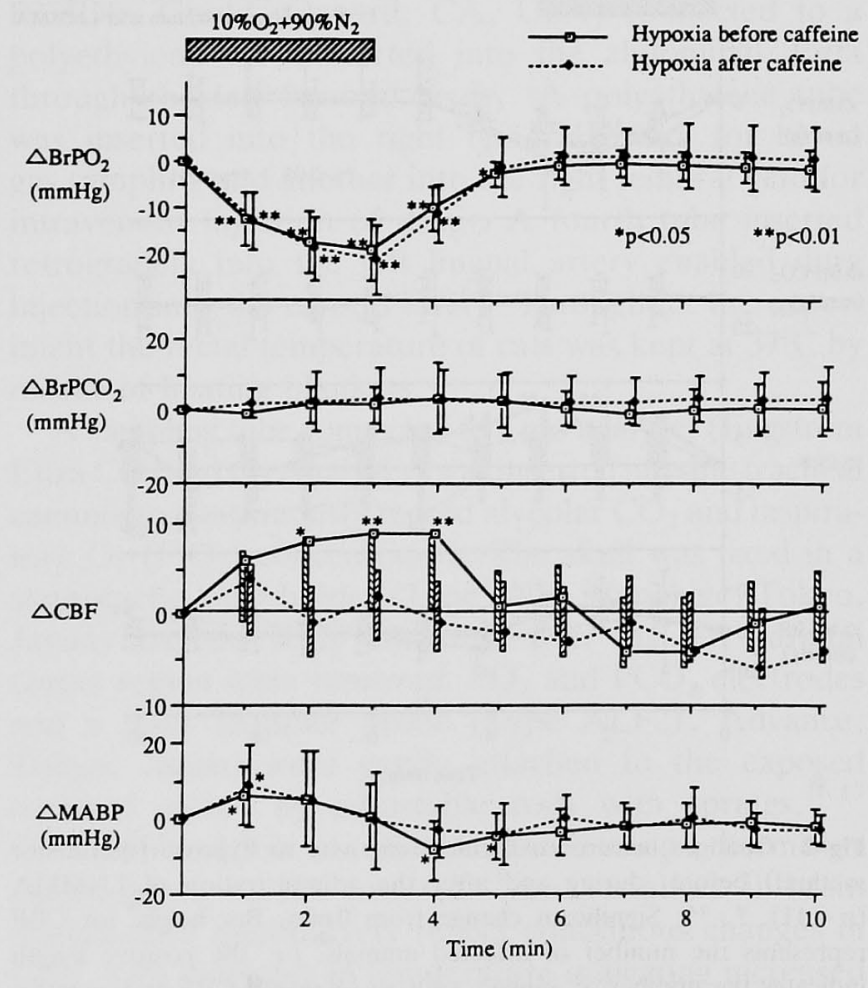

Fig 3 Changes in cerebrovascular reactivity to hypoxia (thermistor method) before and after the administration of caffeine $(n=10) .{ }^{*}, * *$. Significant change from $0 \mathrm{~min}$. See Fig 2 for explanation of CBF results. cerebral metabolism in the present experimental condition. Because no difference was observed between the amount of decrease in $\mathrm{BrPO}_{2}$ or increase in MABP before and after the administration, this leads to a similar conclusion for caffeine as was obtained in Experiments 1 and 2 for indomethacin and LNMMA, respectively.

\section{Discussion}

Since laser Doppler and thermistor methods have less or no quantitative basis in comparison with, for example, the hydrogen clearance method, ${ }^{16-18}$ some limitations exist in interpreting our results. However, these two techniques are presently the most reliable ones for obtaining continuous CBF data recording. Although hypoxia induced by a 3-min inhalation of a mixture of $10 \% \mathrm{O}_{2}+90 \% \mathrm{~N}_{2}$ is relatively mild, ${ }^{1,2}$ it nonetheless reduces the $\mathrm{PaO}_{2}$ level below $50 \mathrm{mmHg}$ (Table 1). Therefore, we consider this method to be an effective way to simulate hypoxic hyperemia.

Sakabe and Siesjö ${ }^{19}$ observed no relationship between prostacyclin and hypoxic hyperemia, whereas McCalden et al $^{20}$ obtained opposite results. Here, CBF augmentation during hypoxia was suppressed by the administration of indomethacin, a competitive cyclooxygenase inhibitor; thereby suggesting that prostacyclin participates in such augmentation. A hypothesized reactivity mechanism is described as follows. Depolarization of the endothelial cell membrane under brain hypoxia causes an influx of $\mathrm{Ca}^{2+}$ ions with intracellular free $\mathrm{Ca}^{2+}$ accumulating. Consequently, phospholipase $\mathrm{A}_{2}$ is activated, cell membrane phospholipids are hydrolysed, and free fatty acids are released. ${ }^{21}$ The resynthesis (reacylation) from free fatty acids to phospholipids in known to be disturbed by the depletion of ATP, and so free fatty acids, particularly arachidonic acid, accumulate. ${ }^{4}$ This increase in arachidonic acid would then be metabolized to prostacyclin by cyclooxygenase, and since endotheliumderived prostacyclin dilates vascular smooth muscle and indomethacin inhibits the cyclooxygenase pathway, conversion from arachidonic acid to cyclic endoperoxide is suppressed; hence prostacyclin is no longer formed ${ }^{22}$ and hypoxic hyperemia is ultimately repressed.

Until recently, only a limited number of studies have addressed the relationship between NO and hypoxic hyperemia in the brain in vivo. Kozniewska et al ${ }^{11}$ concluded that $\mathrm{NO}$ modulates hypoxic changes of $\mathrm{CBF}$, but that this is probably not the main factor responsible for increases in CBF. Pelligrino et al $l^{9}$ also reported that NO synthesis is critically involved in the cerebral hyperemic response to hypercapnia but not to hypoxia. Nevertheless, here we clearly demonstrate that CBF augmentation during hypoxia is suppressed by the administration of LNMMA, a competitive NOS inhibitor; suggesting NO participates in this augmentation. The reactivity 
mechanism in this case is hypothesized as follows. NO release from the endothelium has been found to increase under hypoxia. ${ }^{23}$ In such a condition, the intracellular free $\mathrm{Ca}^{2+}$ ions in the endothelium increase and activate NOS, and this in turn increases NO production from Larginine. ${ }^{24}$ The main action of NO is to stimulate soluble guanylate cyclase which causes an increase in cGMP in vascular smooth muscle. ${ }^{25}$ If LNMMA antagonizes $\mathrm{L}$ arginine and suppresses NO production by NOS, then hypoxic hyperemia would subsequently be repressed.

Phillis et al,${ }^{12}$ Winn et al,${ }^{13}$ Morii et al, ${ }^{14}$ and Puiroud et $a l^{15}$ have all investigated the relationship between adenosine and hypoxic hyperemia and provided supportive data, yet it has still not been determined whether the increase in adenosine during hypoxic hyperemia is the cause or result. ${ }^{13}$ As shown in Fig 3, CBF augmentation during hypoxia was suppressed by the administration of caffeine, a competitive adenosine antagonist, suggesting that adenosine participates in CBF augmentation during hypoxia. The reactivity mechanism is hypothesized as follows. Under hypoxia, cytosolic adenosine of brain parenchyma increases by metabolic processes such as the degradation of ATP to adenosine. Cytosolic adenosine is then released outside the cell by a nucleoside transporter. Adenosine's action is mediated by receptors on the cell surface which are classified as $A_{1}, A_{2}$, and $A_{3}$ receptors. In fact, vascular dilatation by adenosine is known to be mediated by the $A_{2}$ receptor. ${ }^{26}$ Since adenosine can activate adenylate cyclase through the $A_{2}$ receptor of vascular smooth muscle and stimulate production of cyclic AMP, the influx of $\mathrm{Ca}^{2+}$ ions from outside the smooth muscle cell and $\mathrm{Ca}^{2+}$ release from sarcoplasmic reticulum would consequently be inhibited and dilation of the vascular smooth muscles occure. As caffeine blocks adenosine receptors, this prevents muscle dilation even though the amount of adenosine increases due to hypoxia.

Apart from the cerebral circulation, a multifactorial hypoxic coronary vasodilatation hypothesis has been proposed for the coronary circulation, i.e. Park et $a l^{27}$ reported that NO is an important mediator of the early phase of hypoxic coronary vasodilation, whereas additional mechanisms and/or factors, including adenosine and vasodilatatory prostaglandins, contribute to the late phase. This hypothesis is supported in the present study because we confirmed that CBF augmentation during hypoxia is suppressed by inhibition of either prostacyclin production, NO production, or adenosine action. These results subsequently suggest that prostacyclin $\left(\mathrm{PGI}_{2}\right)$, nitric oxide (NO), and adenosine may jointly participate in CBF augmentation during hypoxia. In addition, a possibility may exist for the multifactorial regulation of hypoxic hyperemia by endothelium-derived and brain parenchyma-derived substances.

\section{References}

1. Meyer JS, Gotoh F, Ebihara S, Tomita M: Effects of anoxia on cerebral metabolism and electrolytes in man. Neurology 1965, 15: 892-901

2. Kogure K, Scheinberg P, Reinmuth OM, Fujishima M, Busto R: Mechanisms of cerebral vasodilatation in hypoxia. J Appl Physiol 1970, 29: 223-229

3. Pickard JD, Mackenzie ET: Inhibition of prostaglandin synthesis and the response of baboon cerebral circulation to carbon dioxide. Nature New Biol 1973, 245: 187-188

4. Gaudet RJ, Alam I, Levine L: Accumulation of cyclooxygenase products of arachidonic acid metabolism in gerbil brain during reperfusion after bilateral common carotid artery occlusion. J Neurochem 1980, 35: 653-658

5. Isozumi $\mathrm{K}$ : The impairment of cerebrovascular $\mathrm{CO}_{2}$ responsiveness during hypoglycemia and its recovery by administration of prostacyclin. Keio Igaku (J Keio Med Soc) 1990, 67: 75-87 (in Japanese)

6. Moncada S: Biology and therapeutic potential of prostacyclin. Stroke 1983, 14: 157-168

7. Furchgott RF, Zawadzki JV: The obligatory role of endothelial cells in the relaxation of arterial smooth muscle by acetylcholine. Nature 1980, 288: 373-376

8. Palmer RMJ, Ferrige AG, Moncada S: Nitric oxide release accounts for the biological activity of endothelium-derived relaxing factor. Nature 1987, 327: 524-526

9. Pelligrino DA, Koenig HM, Albrecht RF: Nitric oxide synthesis and regional cerebral blood flow responses to hypercapnia and hypoxia in the rat. J Cereb Blood Flow Metab 1993, 13: 80-87

10. Tanaka K, Gotoh F, Gomi S, Takashima S, Mithara B, Shirai T, Nogawa $S$, Nagata E: Inhibition of nitric oxide synthesis induces a significant reduction in local cerebral blood flow in the rat. Neurosci Lett 1991, 127: 129-132

11. Kozniewska E, Oseka M, Stys T: Effects of endothelium-derived nitric oxide on cerebral circulation during normoxia and hypoxia in the rat. J Cereb Blood Flow Metab 1992, 12: 311-317

12. Phillis JW, Walter GA, O'Regan MH, Stair RE: Increases in cerebral cortical perfusate adenosine and inosine concentrations during hypoxia and ischemia. J Cereb Blood Flow Metab 1987, 7: $679-686$

13. Winn HR, Rubio GR, Berne RM: The role of adenosine in the regulation of cerebral blood flow. J Cereb Blood Flow Metab 1981, 1: 239-244

14. Morii S, Ngai AC, Ko KR, Winn HR: Role of adenosine in regulation of cerebral blood flow: effects of theophylline during normoxia and hypoxia. Am J Physiol 1987, 253: H165-H175

15. Puiroud S, Pinard E, Seylaz J: Dynamic cerebral and systemic circulatory effects of adenosine, theophylline and dipyridamole. Brain Res 1988, 453: 287-298

16. Meyer JS, Gotoh F, Tazaki Y, Hamaguchi K, Ishikawa S, Nouailhat F, Symon L: Regional cerebral blood flow and metabolism in vivo: effects of anoxia, hypoglycemia, ischemia, acidosis, alkalosis, and alterations of blood $\mathrm{PCO}_{2}$. Arch Neurol 1962, 7: 560-581

17. Skarphedinsson JO, Hårding H, Thorén P: Repeated measurements of cerebral blood flow in rats. Comparisons between the hydrogen clearance method and laser Doppler flowmetry. Acta Physiol Scand 1988, 134: 133-142

18. Isozumi K, Izumi Y, Fukuuchi Y, Gotoh F: Effects of mergocriptine on cerebral circulation and metabolism in cats. Arzneimittelforschung 1992, 42: 901-903

19. Sakabe T, Siesjö BK: The effect of indomethacin on the blood flow-metabolism couple in the brain under normal, hypercapnic and hypoxic conditions. Acta Physiol Scand 1979, 107: 283-284 
20. McCalden TA, Nath RG, Thiele $K$ : The role of prostacyclin in the hypercapnic and hypoxic cerebrovascular dilations. Life Sci 1984, 34: 1801-1807

21. Rehncrona S, Westerberg E, Åkesson B, Siesjö BK: Brain cortical fatty acids and phospholipids during and following complete and severe incomplete ischemia. J Neurochem 1982, 38: 84-93

22. Vane JR: Inhibition of prostaglandin synthesis as a mechanism of action for aspirin-like drugs. Nature New Biol 1971, 231: 232-235

23. Pearce WJ, Ashwal S, Cuevas J: Direct effects of graded hypoxia on intact and denuded rabbit cranial arteries. Am J Physiol 1989. 257: $\mathrm{H} 824-\mathrm{H} 833$
24. Pohl U, Busse R: Hypoxia stimulates release of endotheliumderived relaxant factor. Am J Physiol 1989, 256: H1595-H1600

25. Moncada S, Palmer RMJ, Higgs EA: The discovery of nitric oxide as the endogenous nitrovasodilator. Hypertension 1988, 12: $365-372$

26. Ribeiro JA, Sebastiao AM: Adenosine receptors and calcium: basis for proposing a third $\left(\mathrm{A}_{3}\right)$ adenosine receptor. Prog Neurobiol 1986, 26: 179-209

27. Park KH, Rubin LE, Gross SS, Levi R: Nitric oxide is a mediator of hypoxic coronary vasodilatation. Relation to adenosine and cyclooxygenase-derived metabolites. Circ Res 1992, 71: 992-1001 